\title{
MiR-155, a potential serum marker of extramammary Paget's disease
}

\author{
Hao Guo ${ }^{1}$, Rui-Qun Qi ${ }^{1}$, Jie Sheng ${ }^{2}$, Chang Liư ${ }^{3}$, Hang Ma ${ }^{3}$, He-Xiao Wang ${ }^{1}$, Jiu-Hong Li ${ }^{1}$, Xing-Hua Gao ${ }^{1}$, \\ Yin-Sheng Wan ${ }^{4}$ and Hong-Duo Chen ${ }^{1 *}$
}

\begin{abstract}
Background: Extramammary Paget's disease (EMPD), a rare skin malignancy with non-specific manifestations, is often misdiagnosed as eczema of scrotum or tinea cruris. Although the diagnosis of EMPD could be confirmed by biopsy, it can be delayed as patients are reluctant to receive invasive operations. Herein, we investigated the serum miRNA expressions of EMPD patients and compared to that of the eczema of scrotum or tinea cruris patients as well as health volunteers for potential diagnostic markers for EMPD.
\end{abstract}

Methods: Altogether 45 subjects including 16 patients diagnosed with EMPD, 12 patients diagnosed with eczema of scrotum or tinea cruris and 17 healthy volunteers were enrolled in this study. Serum from all of subjects were collected to identify miRNAs (by miRNA array global normalization, RT-PCR validation, and receiver operating characteristic curve analysis) that could be potential diagnostic markers for EMPD.

Results: The miRNA array analyses revealed that the expressions of 37 miRNAs from the EMPD patients were different (change $\geq 4$-fold) from health volunteers. Among these miRNAs, the expression of miR-155 was significantly increased $(p<0.01)$ in the EMPD patients as compared with that of the health volunteers and the eczema of scrotum or the tinea cruris patients (no difference between these two control groups). In addition, receiver operating characteristic $(\mathrm{ROC})$ curve analysis showed that diagnostic capacities (defined as the area under curve of ROC) of miR-155 are 0.85 (as compared with health volunteers group) and 0.81 (as compared with the eczema of scrotum or the tinea cruris patients group), respectively.

Conclusion: The serum miRNA expression of gene miR-155 in the EMPD patients was differentiated from that of other subjects warranting further validation of miR-155 as a diagnostic marker of EMPD.

Keywords: General dermatology, MiR-155, Extramammary Paget's disease

\section{Introduction}

Extramammary Paget's disease (EMPD) is a rare cutaneous malignancy that affects apocrine-rich areas such as the vulva, penis, scrotum and perianal area [1]. Its clinical manifestations are not specific and can be presented as erythematous patches, plaques or erosions, occasionally with adherent crust [2]. Patients may also experience symptoms of pruritus and tenderness [1-3]. Therefore, EMPD is also known as "eczematoid carcinoma" as it can be misdiagnosed as eczema of scrotum (ECZ) or tinea cruris (TIN) at the early stage. In the clinic, without

\footnotetext{
*Correspondence: hongduochen@hotmail.com; chenhd@cae.cn ${ }^{1}$ Department of Dermatology, No.1 Hospital of China Medical University, 155N. Nanjing Street, Shenyang 110001, People's Republic of China Full list of author information is available at the end of the article
}

proper histopathological examinations, EMPD patients with unspecific manifestations are often misdiagnosed as ECZ/TIN. Topical treatments may relieve symptoms of ECZ/TIN (such as pruritus), it gives an illusion of false improvement which leads to further delayed diagnosis of EMPD. It is reported that EMPD has a median delayed diagnosis of 2 years due to the aforementioned reasons $[2,4]$. Although biopsy is the gold standard for diagnosis of EMPD, some suspected EMPD patients are reluctant to receive biopsy due to the invasiveness of the procedure. Therefore, investigations of noninvasive markers to improve the diagnosis of EMPD are of great research interest.

MicroRNAs (miRNAs) are a class of 19-25-nucleotide noncoding RNAs that have been implicated in the

(c) The Author(s). 2018 Open Access This article is distributed under the terms of the Creative Commons Attribution 4.0 International License (http://creativecommons.org/licenses/by/4.0/), which permits unrestricted use, distribution, and reproduction in any medium, provided you give appropriate credit to the original author(s) and the source, provide a link to the Creative Commons license, and indicate if changes were made. The Creative Commons Public Domain Dedication waiver (http://creativecommons.org/publicdomain/zero/1.0/) applies to the data made available in this article, unless otherwise stated. 
regulations of various cellular processes [5]. Some miRNAs have been reported to have significant correlations with cancer development and progression. They have been investigated as circular markers of many malignancies $[6,7]$. In our previous study, miRNAs including miR-31, miR-375 and miR-31* were overexpressed in EMPD tissue as compared to normal keratinocytes and normal apocrine glands (the historical origin of EMPD) using laser-capture microdissection in frozen tissues from 12 EMPD patients [8]. However, to date, neither serum miRNAs of EMPD have been investigated, nor serum markers were validated in clinics for the diagnosis of EMPD. Herein, we investigated expressions of miRNAs from human subjects using miRNA array analyses to identify specific miRNAs for potential diagnostic serum markers of EMPD.

\section{Patients and methods}

\section{Study population}

The study was approved by ethics committee of No. 1 Hospital of China Medical University (No. AF-SOP07-1.0-01).

Patients and healthy volunteers were enrolled from No.1 Hospital of China Medical University from 2014 to 2017. Healthy volunteers (17), EMPD patients (16), ECZ/TIN patients (12) were archived and enrolled in this study. Clinical basic characteristics of the volunteers and patients were summarized in Table 1 . To minimize the heterogeneity in our enrolled cases, females were

Table 1 Demographics and clinical features

\begin{tabular}{llll}
\hline Characteristics & Normal & EMPD & ECZ/ TIN \\
\hline $\begin{array}{l}\text { Sample size, } n \\
\text { Gender, } n\end{array}$ & 17 & 16 & $12\left(\mathrm{n}_{\mathrm{TIN}}=7 ; \mathrm{n}_{\mathrm{ECZ}}=5\right)$ \\
$\quad$ Male & 17 & 16 & 12 \\
$\quad$ Female & 0 & 0 & 0 \\
Age, years & $61.8 \pm 8.7$ & $63.7 \pm 8.4$ & $58.2 \pm 11.7$ \\
Primary site, $n$ & & & \\
Penis & 1 & 0 \\
Scortum & 5 & 5 \\
Scortum \& penis & 1 & 0 \\
Gorin (including thigh) & 5 & 4 \\
Scortum \& gorin & 4 & 3 \\
Size of lesion (cm ${ }^{2}$ ), $n$ & & \\
$<10$ & 2 & 1 \\
$10-19$ & 4 & 4 \\
$20-29$ & 6 & 4 \\
$29-39$ & 3 & 3 \\
$>39$ & 1 & 0 \\
\hline
\end{tabular}

excluded in this study. All of the patients and healthy volunteers came from the region of northeastern of China.

Enrolled healthy volunteers (normal group) were excluded from any malignancies, allergic dermatisis, infections and certain internal diseases through physical examinations as normal control.

EMPD patients (EMPD group), diagnosed via histopathological examination, were ruled out of diseases including allergic dermatisis, infections, EMPD metastasis and other malignancies via comprehensive examinations (including chest $\mathrm{CT}$, abdominal \& urinary system B ultrasonic and enteroscope).

Eczema of scrotum or tinea cruris patients (ECZ/TIN group) were diagnosed via comprehensive physical and dermatological examinations (including blood routine, total IgE and fungus microscope examination). They were ruled out of other infections and malignancies via comprehensive examinations.

\section{RNA isolation}

Blood samples were collected form enrolled patients and volunteers. Serum from blood samples were prepared through a centrifuge at $4000 \mathrm{rpm}$ for $15 \mathrm{~min}$. Collected serum samples were extracted for total RNA including miRNAs by Qiagen miRNeasy Micro Kit accordingly to the manufacture's protocol with minor modifications. Briefly, serum from each sample was lysed with QIAzol lysis reagent and then $100 \mathrm{uL}$ of chloroform were added. Next, samples were centrifuged for $15 \mathrm{~min}$ at $12000 \mathrm{xg}$ at $4{ }^{\circ} \mathrm{C}$. The upper aqueous phase of each sample was transferred and 1.5 times of volumes of $100 \%$ ethanol were added. Then mixtures went through the RNeasy Micro spin column and $40 \mathrm{ul}$ RNase free water were used to elute. The volume of each sample was reduced to $15-20$ ul by vacuo. RNA quantity (15-20 $\mathrm{ng} / \mathrm{ul}$ ) and quality (OD 260/280 was approximately 1.0 with a peak at $270 \mathrm{~nm}$ ) were assessed with the ThermoScientific NanoDrop 2000 (Thermo Fisher Scientific, Inc., Franklin, MA, USA).

\section{TaqMan low-density array miRNA qRT-PCR}

Due to the limited RNA obtained from serum, a pre-amplification step was added as per manufacture's protocol when miRNA array was performed in 2 samples of normal and 2 samples of EMPD in both groups for screening.

The reversed transcription of RNA was prepared using the TaqMan MiRNA Reverse Transcription Kit and TaqMan MiRNA Multiplex RT Assays (human pool A; V2.1). RNA (3 ul) was added to each reaction and RT-PCR was carried on an ABI Veriti Thermal cycler (Applied Biosystems, Foster City, CA, USA). The product $(2.5 \mathrm{ul})$ from each reaction was pre-amplified as 
per manufacturer's protocol with the Megaplex PreAmp Primers (10×), Human pool A (V2.1) and TaqMan PreAmp Master Mix $(2 \times)$. Then miRNA expression was profiled with TaqMan Human MicroRNA array card A (V2.1), performed on a 7900HT Fast Real-Time PCR System (Applied Biosystems, Foster City, CA, USA), using the manufacturer's recommended protocol.

\section{Global normalization}

Raw cycle threshold $(\mathrm{Ct})$ values were calculated using SDS 2.3 and RQ manager 1.2 software (Applied Biosystems, Foster City, CA, USA) using default baselines and threshold settings. All the $\mathrm{Ct}$ values were exported into StatMiner 4.2 (Integromics ${ }^{\circledast}$ Inc., Philadelphia, PA, USA) for global normalization. The miRNAs detected in

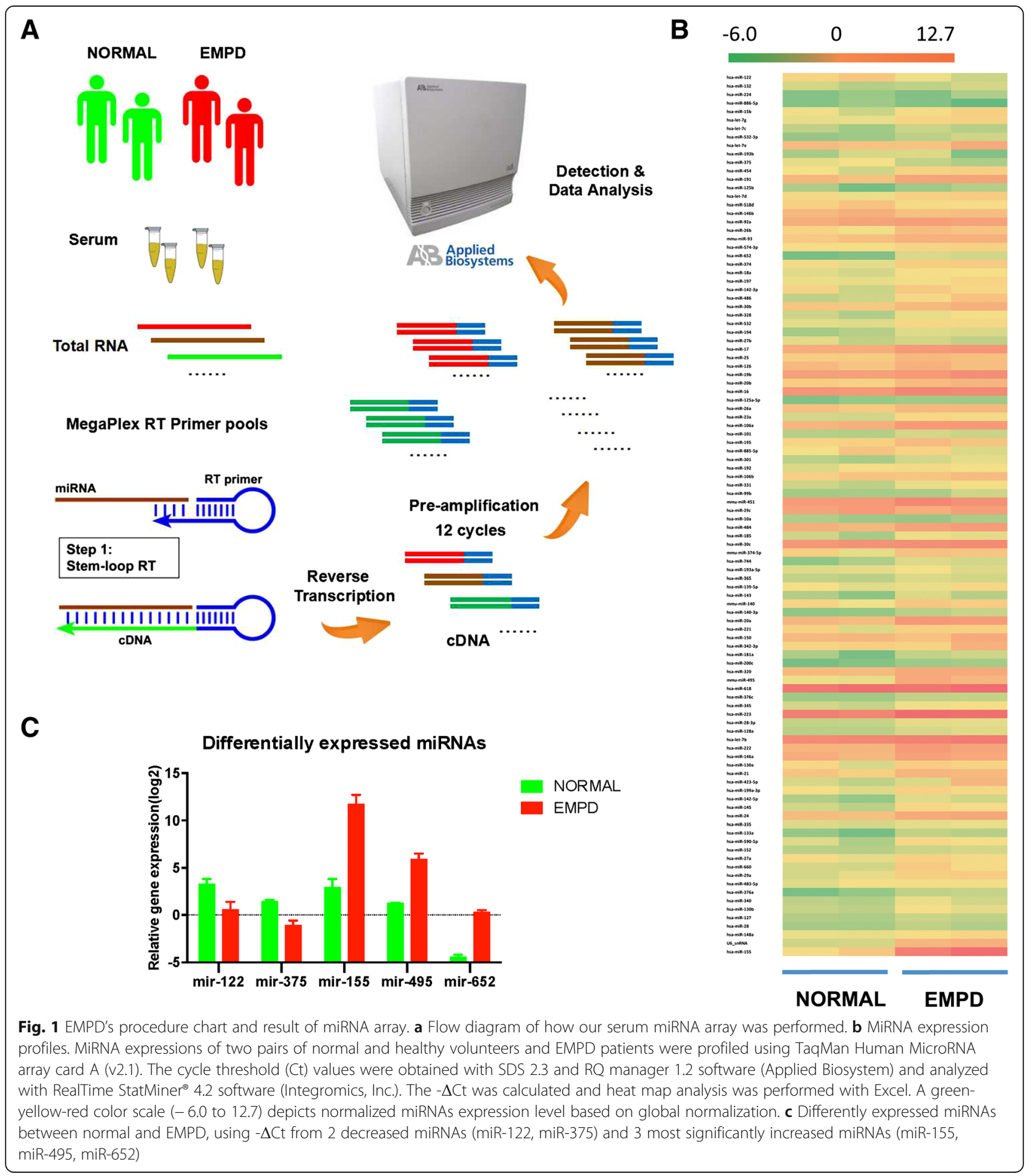


all of the samples were used for global normalization. The mean $\mathrm{Ct}$ value of each individual sample was calculated by the global normalization, and subtracts the $\mathrm{Ct}$ value from each miRNA of the same sample to obtain the $\Delta \mathrm{Ct}$ value. The miRNAs that were expressed in all samples were considered meaningful for further data analysis. Heat-map analysis was performed using $\Delta \mathrm{Ct}$ with hierarchical clustering using miRNAs expressed in all 4 samples. Average $\Delta C t$ of normal and EMPD were calculated separately, the $\Delta \Delta \mathrm{Ct}\left(\Delta \mathrm{Ct}_{\mathrm{NORMAL}}-\Delta \mathrm{Ct}_{\mathrm{EMPD}}\right)$ was also calculated for further study.

\section{RT-PCR}

After significantly different expressed miRNAs were obtained, specific RT-PCR analyses were performed (15 normal, 14 EMPD as well as 12 ECZ/TIN). The RNA was reverse transcribed using the TaqMan MiRNA Reverse Transcription Kit. Then RT- PCR was performed following protocols provided by TaqMan.

\section{Statistical analysis}

For all samples in RT-PCR, cycle threshold (Ct) values were obtained with SDS 2.3 and RQ manager 1.2 software (Applied Biosystems, Foster City, CA, USA). Expressions of miRNAs were calculated with StatMiner $^{\bullet} 4.2$ (Integromics $^{\circ}$ Inc., Philadelphia, PA, USA) using $-\Delta \mathrm{Ct}^{*}\left[-\left(\mathrm{Ct}-\mathrm{Ct}_{\mathrm{mir}-374-5 \mathrm{p}}\right)\right]$ of each sample. Bonferroni's Multiple Comparison Test was used to compare the $\left(-\Delta C t^{*}\right)$ value among the three groups. $P$-value $<0.05$ are considered significantly different between two groups. Receiver Operating Characteristic (ROC) curve analysis was then performed using the differentially expressed miRNA. Scattergraph and ROC curve analysis were both performed by GraphPad Prism.

\section{Results}

\section{MiRNA array and global normalization}

The miRNA gene expression profiles were obtained from two normal and two EMPD patients (flow diagram showed how serum miRNA arrays analyses shown in Fig. 1a). A total of 255 miRNAs were detected in the TaqMan $^{\circ}$ Array MicroRNA human card A. In average 166 miRNAs were detected per sample, and $105 \mathrm{miR}$ NAs were detected in all the samples. For each sample, the global mean value of the expression of the $105 \mathrm{miR}$ NAs was calculated, then the difference $(\Delta C \mathrm{t})$ between the expression of each individual miRNA in this given sample and the global mean was obtained. Heat-map analysis showed that most of miRNAs' expressions were relatively consistent across different samples. The heat-map indicated that global normalization reduced the variations, and the overall miRNA gene expression profiles between different individuals were consistent (Fig. 1b). Some miRNAs showed difference between normal and EMPD groups [miRNAs $(|\Delta \Delta \mathrm{Ct}| \geq 2)]$ and were defined as potentially different. Expression of 2 miRNAs were down-regulated and 35 miRNAs were up-regulated (Table 2).

Table 2 Differentially expressed miRNAs in array

\begin{tabular}{|c|c|c|c|c|c|}
\hline miRNAs & $\Delta \mathrm{Ct}_{\text {Normal-1 }}$ & $\Delta \mathrm{Ct}_{\text {Normal-2 }}$ & $\Delta \mathrm{Ct}_{\text {EMPD-1 }}$ & $\Delta \mathrm{Ct}_{\text {EMPD-2 }}$ & $\Delta \Delta \mathrm{Ct}$ \\
\hline hsa-miR-375 & -1.2 & -1.6 & 0.6 & 1.6 & -2.5 \\
\hline hsa-miR-122 & -2.7 & -3.8 & -1.4 & 0.3 & -2.7 \\
\hline hsa-miR-155 & -2.0 & -3.8 & -10.7 & -12.7 & 8.8 \\
\hline hsa-miR-652 & 4.7 & 4.2 & -0.5 & -0.1 & 4.8 \\
\hline mmu-miR-495 & -1.3 & -1.2 & -6.5 & -5.3 & 4.7 \\
\hline hsa-miR-486 & 0.8 & 0.1 & -2.2 & -4.1 & 3.6 \\
\hline hsa-miR-376a & 4.7 & 3.0 & 0.8 & 0.4 & 3.3 \\
\hline hsa-miR-423-5p & -0.4 & 0.8 & -0.5 & -5.2 & 3.11 \\
\hline hsa-miR-133a & 3.0 & 4.9 & 0.7 & 1.2 & 3.0 \\
\hline hsa-miR-20a & -5.2 & -4.6 & -8.2 & -7.7 & 3.0 \\
\hline hsa-miR-181a & 1.7 & 4.6 & 0.6 & 0.1 & 2.79 \\
\hline hsa-miR-744 & 3.2 & 1.5 & -0.7 & -0.1 & 2.75 \\
\hline hsa-miR-660 & -0.3 & 0.0 & -3.5 & -2.1 & 2.63 \\
\hline hsa-miR-29a & -0.1 & -1.2 & -3.1 & -3.4 & 2.6 \\
\hline hsa-miR-142-5p & 1.4 & 3.0 & -0.8 & 0.0 & 2.6 \\
\hline hsa-miR-145 & -0.1 & 0.9 & -2.4 & -1.9 & 2.6 \\
\hline hsa-miR-590-5p & -0.7 & 1.6 & -2.3 & -1.7 & 2.4 \\
\hline hsa-miR-106a & -5.4 & -5.9 & -8.0 & -8.0 & 2.4 \\
\hline hsa-miR-328 & 0.3 & 1.5 & -1.2 & -1.7 & 2.4 \\
\hline hsa-miR-140-3p & 3.2 & 3.0 & 1.1 & 0.4 & 2.35 \\
\hline hsa-miR-194 & 2.2 & 1.3 & -0.8 & -0.4 & 2.4 \\
\hline hsa-miR-532-3p & 2.9 & 2.4 & 0.9 & 0.0 & 2.2 \\
\hline hsa-miR-23a & -0.1 & 0.0 & -2.4 & -2.1 & 2.2 \\
\hline hsa-miR-223 & -10.6 & -10.1 & -12.8 & -12.3 & 2.2 \\
\hline hsa-miR-26b & -2.6 & -1.5 & -4.6 & -3.8 & 2.2 \\
\hline hsa-miR-17 & -6.0 & -6.0 & -8.1 & -8.3 & 2.2 \\
\hline hsa-miR-185 & 0.0 & 1.9 & -1.3 & -1.0 & 2.1 \\
\hline hsa-miR-20b & -3.2 & -2.6 & -4.8 & -5.2 & 2.1 \\
\hline hsa-miR-454 & -1.6 & 0.0 & -2.6 & -3.1 & 2.1 \\
\hline hsa-miR-143 & 1.4 & 3.4 & -0.6 & 1.2 & 2.1 \\
\hline hsa-miR-191 & -5.2 & -4.2 & -6.7 & -6.7 & 2.0 \\
\hline hsa-miR-15b & -1.4 & 0.3 & -2.0 & -3.1 & 2.0 \\
\hline hsa-miR-130b & 0.4 & 0.9 & -1.7 & -1.0 & 2.0 \\
\hline hsa-miR-200c & 4.6 & 3.9 & 2.6 & 2.0 & 2.0 \\
\hline hsa-miR-301 & 1.0 & 1.9 & -0.1 & -1.0 & 2.0 \\
\hline hsa-miR-222 & -5.5 & -5.3 & -7.8 & -6.9 & 2.0 \\
\hline hsa-miR-484 & -5.7 & -5.1 & -7.0 & -7.7 & 2.0 \\
\hline
\end{tabular}


MiR-155 was found obviously up-regulated in EMPD serum The 2 down-regulated miRNAs (miR-122 and miR-375) and 3 up-regulated miRNAs with largest $|\Delta \Delta \mathrm{Ct}|$ (miR-155, miR-495, and miR-652) were selected for further validation (Fig. 1c).

Then RT-PCR of the above 5 miRNAs among normal, EMPD as well as ECZ/TIN groups (the differential diagnosis group) were performed. Bonferroni's Multiple Comparison Test was carried out among three groups. Expression levels of miR-122, miR-375, miR-495 and miR-652 showed no difference among three groups (Fig. 2). Expression of miR-155 significantly increased in the EMPD group as compared to other groups and there is no difference between normal and ECZ/TIN (Fig. 2c) groups. We combined data from two common differential diagnosis diseases, ECZ/TIN, together as one group due to the limited patient number we enrolled.
ROC curve analysis of serum miR-155 of EMPD

The expression of miRNA-155 showed significant increase as compared to normal and common differential diagnosis diseases, which suggested that miRNA-155 may be a potential serum marker of EMPD diagnosis. Furthermore, ROC curve analysis of miR-155 was established based on three groups. Our results showed that miR-155 could accurately distinguish patients of EMPD from healthy volunteers with AUC (area under curve) of 0.85 (Fig. 2f). Similarly, this marker could distinguish patients with EMPD from patients with ECZ/TIN with AUC of 0.81 (Fig. 2g).

\section{Discussion}

Paget's disease is a rare cutaneous intraepithelial malignancy characterized by Paget cells (large cytoplasm and mucin rich adenocarcinoma cells) [9]. It has two

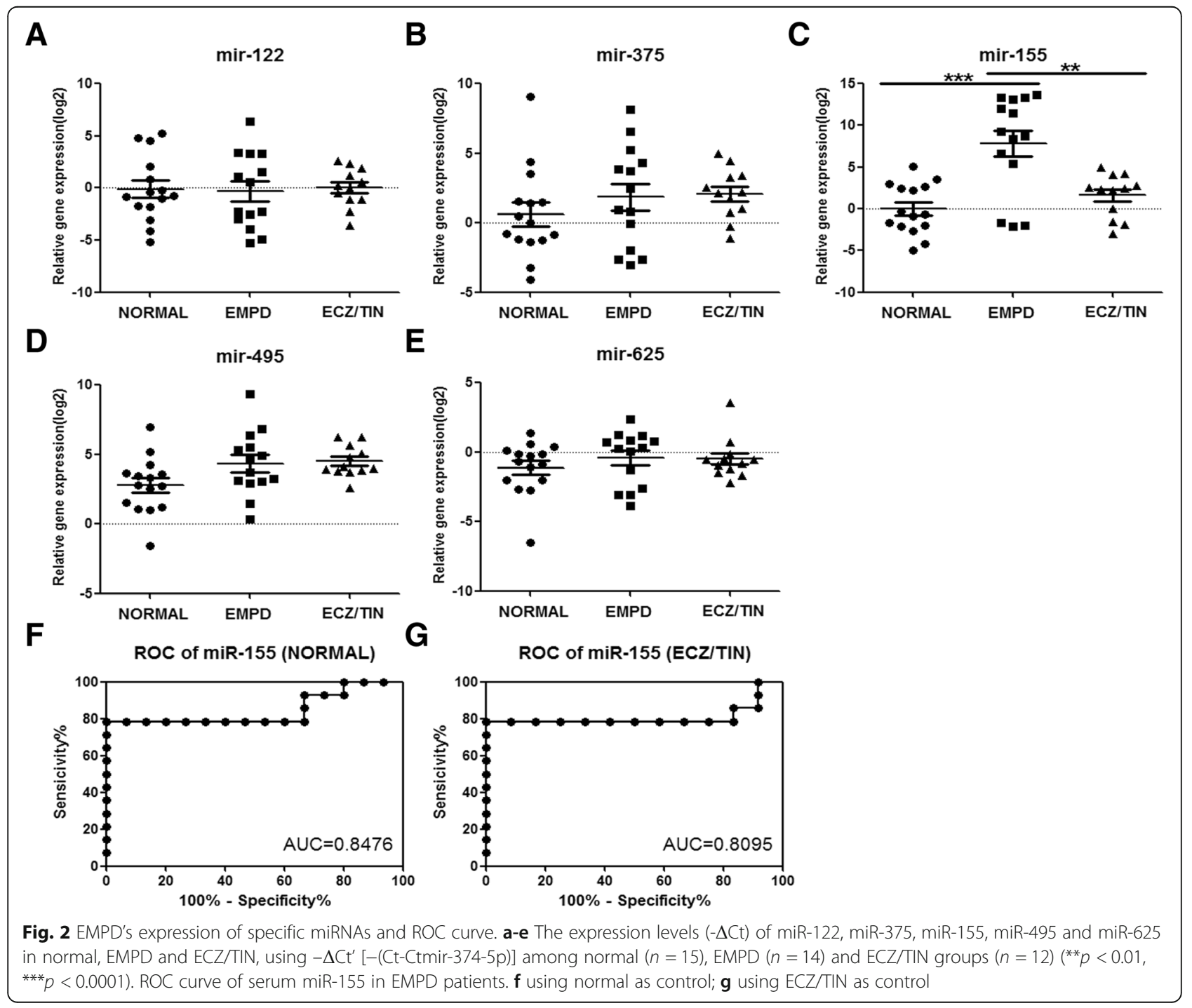


subtypes according to the affected anatomic location: mammary Paget's diseases and EMPD. The mammary Paget disease was first found by James Paget in 1874, it was reported as an intraepithelial breast carcinoma and suggested that the pattern may be found in other parts [10]. EMPD was first described by Crocker in 1888 [10].

EMPD has unspecific manifestations and can be misdiagnosed as ECZ/TIN. It also has a high recurrence rate after surgery treatment due to the subclinical extension and the multifocal feature [2, 11-14]. Therefore, researches have been focusing on investigations of serum markers aiming to improve the diagnosis and prognosis $[15,16]$. Circular miRNAs have been extensively investigated as biomarkers helping with the diagnosis during the past decade [17]. For this current study, a major finding was that miR-155 was significantly increased in the serum of EMPD patients. We sought to identify several promising serum markers, and use the combination of serum markers as a diagnostic method. However, the results of miR-122, miR-375, miR-495 and miR-625 showed no difference between normal and EMPD groups which were differentially expressed in array. This might be caused by the heterogeneity among patients and the limited number enrolled in the array analyses. Based on our previous studies, the serum miRNAs varied immensely among patients [18]. This study was performed on small sample size, and all the other published serum markers of EMPD were based on small sample size research due to the rarity of the disease $[15,16]$. We suggest the specific expressed miR-155 can be used and/or in combination with other serum markers including CEA and Cytokeratin 19 fragment $21-1$ to improve the diagnosis after further validation $[15,16]$.

In Fig. 2, three EMPD patients showed relative low expression of serum miR-155. However, no specific clinical features in age, tumor site, tumor size, tumor depth, and appendages involvement in pathology were observed in these patients. It is reported that $>93 \%$ of mammary Paget's diseases was associated with underlying ductal breast cancer [19]. In addition, 29\% of EMPD patients were associated with internal malignancies including breast cancer, colorectal cancer, prostate cancer, bladder cancer and gastric cancer [20]. Therefore, EMPD is likely associated with internal malignancies with contiguous epithelium [2]. The EMPD in perianal area is more likely associated with underlying colorectal cancer, while EMPD in scrotum or vulvar have a high incidence of prostate cancer [2].

A large body of evidence reveals that EMPD is an adenoma the histogenetic origin from apocrine glands [1, 21-27]. In histological study, mammary glands and apocrine glands have the same apocrine secretion pattern. Some immunohistochemical marker of EMPD are also positive in specific type of breast cancer such as human epidermal growth factor receptor 2 (Her2/erbB2), carcinoembryonic antigen (CEA), cytokeratin 7 (CK7) and gross cystic disease fluid protein 15 (GCDFP15) $[1,23,28-32]$. These markers are also positive in other cancers such as prostate adenocarcinoma (Her2/erbB2, CK7 and GCDFP15) [33-35] and colon cancer (Her2/erbB2 and CEA) [34, 36, 37]. The above evidence suggested that EMPD may have common features with breast cancer, prostate cancer and colon cancer as they are all adenocarcinomas and have a high incidence of co-existence. In our current study, we found the expression of miRNA-155 significantly increased as compared to healthy volunteers and common differential diagnosis diseases. In our previous study, we performed miRNA arrays between EMPD tissue and peripheral normal skin from the fresh frozen tissue of the same patient using laser-capture microdissection [8]. Data from that study showed that miR-155 was overexpressed in the tissue EMPD $\left(\mathrm{AVE}_{-\triangle \mathrm{Ct}} \mathrm{EMPD}=-19.96\right)$ compared to peripheral normal skin $\left(\mathrm{AVE}_{-} \triangle \mathrm{Ct} \mathrm{CON}=-22.97\right)$ in array [8]. The consistent findings suggest the increased serum miR-155 may be derived from the EMPD tumor tissue. MiR-155 is also overexpressed in the tissue and serum of multiple types of cancers including breast, prostate, and colon cancers [38-44]. MiR-155 is now considered as one of the most familiar onco-miRNAs especially in breast cancer. The overexpressed serum miR-155 in breast cancer has been varifed by different research groups [38-40]. Our result provides new insights that these malignancies may share common features. However, further investigations on the linkage between miR-155 and EMPD are warranted.

\section{Conclusion}

In summary, this is the first study on the serum miRNA expression profile of EMPD patients. Biomarker miR-155 was significantly increased in EMPD patients as compared with the two control groups (health volunteers and ECZ or TIN patients; no difference between these two controls). Therefore, miR-155 could be targeted as a potential diagnostic marker to improve the diagnosis of EMPD warranting further validations.

\section{Abbreviations \\ AUC: Area under curve; CEA: Carcinoembryonic antigen; CK7: Cytokeratin 7: Ct: Cycle threshold; ECZ: Eczema of scrotum; ECZ/TIN: Eczema of scrotum or tinea cruris; EMPD: Extramammary Paget's disease; GCDFP15: Gross cystic disease fluid protein 15; Her2/erbB2: Human epidermal growth factor receptor 2; miRNA: MicroRNA; miRNAs: MicroRNAs; ROC: Receiver Operating Characteristic; TIN: Tinea cruris}

\section{Acknowledgements}

We thank all the doctors and nurses in dermatology department of No.1 Hospital of China Medical University for helping with the patient management of this study. We also thank all the patients and volunteers participated in this study. 


\section{Funding}

This work was supported by China Scholarship Council (201708210229, HG) and New Teacher Grant of China Medical University (XZR20160003, HG) for data collection, analysis and writing the manuscript.

\section{Availability of data and materials}

The datasets used and analyzed during the current study are available from the corresponding author on reasonable request.

\section{Authors' contributions}

HG carried out most of the experiments, organized data for the manuscript and wrote the manuscript. RQQ and JS helped with the study design and data analysis. CL, HM and YSW participated in manuscript drafting. HXW participated in experiment. JHL participated in patient management. XHG and HDC helped with the study design and manuscript modification. All authors read and approved the final manuscript.

\section{Ethics approval and consent to participate}

This work was reviewed and approved by Ethics Committees of No.1 Hospital of China Medical University (No. AF-SOP-07-1.0-01). All patients gave written informed consent.

\section{Consent for publication}

Not applicable.

\section{Competing interests}

The authors declare that they have no competing interests.

\section{Publisher's Note}

Springer Nature remains neutral with regard to jurisdictional claims in published maps and institutional affiliations.

\section{Author details}

${ }^{1}$ Department of Dermatology, No.1 Hospital of China Medical University, 155N. Nanjing Street, Shenyang 110001, People's Republic of China. 2Department of Anesthesiology, No.1 Hospital of China Medical University, 155N. Nanjing Street, Shenyang 110001, People's Republic of China. ${ }^{3}$ Department of Biomedical and Pharmaceutical Sciences, College of Pharmacy, University of Rhode Island, Kingston, RI 02881, USA. ${ }^{4}$ Department of Physiology, Providence College, Providence, RI 02918, USA

\section{Received: 26 February 2018 Accepted: 24 October 2018}

\section{Published online: 07 November 2018}

\section{References}

1. Wagner G, Sachse MM. Extramammary Paget disease - clinical appearance, pathogenesis, management. J Dtsch Dermatol Ges. 2011;9:448-54

2. Lam C, Funaro D. Extramammary Paget's disease: summary of current knowledge. Dermatol Clin. 2010;28:807-26.

3. Padrnos L, Karlin N, Halfdanarson TR. Mayo Clinic Cancer center experience of metastatic Extramammary Paget disease 1998-2012. Rare Tumors. 2016;8:6804.

4. Hatta N, Yamada M, Hirano T, Fujimoto A, Morita R. Extramammary Paget's disease: treatment, prognostic factors and outcome in 76 patients. Br J Dermatol. 2008;158:313-8.

5. Weiland M, Gao XH, Zhou L, Mi QS. Small RNAs have a large impact: circulating microRNAs as biomarkers for human diseases. RNA Biol. 2012;9:850-9.

6. Schultz NA, Dehlendorff C, Jensen BV, Bjerregaard JK, Nielsen KR, Bojesen SE, Calatayud D, Nielsen SE, Yilmaz M, Hollander NH, et al. MicroRNA biomarkers in whole blood for detection of pancreatic cancer. JAMA. 2014;311:392-404

7. Swellam M, Zahran RFK, Abo El-Sadat Taha H, El-Khazragy N, Abdel-Malak C. Role of some circulating MiRNAs on breast cancer diagnosis. Arch Physiol Biochem. 2018. [Epub ahead of print]

8. Guo H, Qi RQ, Lv YN, Wang HX, Hong YX, Zheng S, Li JH, Gao XH, Chen HD miR-31 is distinctively overexpressed in primary male extramammary Paget's disease. Oncotarget. 2016;7:24559-63.

9. Zhou S, Zhong W, Mai R, Zhang G. Mammary and Extramammary Paget's disease presented different expression pattern of steroid hormone receptors. Biomed Res Int. 2017;2017:3768247.
10. Carbotta G, Sallustio P, Prestera A, Laforgia R, Lobascio P, Palasciano N Perineal Paget's disease: a rare disorder and review of literature. Ann Med Surg (Lond). 2016;9:50-2.

11. Murata Y, Kumano K. Extramammary Paget's disease of the genitalia with clinically clear margins can be adequately resected with $1 \mathrm{~cm}$ margin. Eur J Dermatol. 2005;15:168-70.

12. Mohs FE, Blanchard L. Microscopically controlled surgery for extramammary Paget's disease. Arch Dermatol. 1979;115:706-8.

13. O'Connor WJ, Lim KK, Zalla MJ, Gagnot M, Otley CC, Nguyen TH, Roenigk RK. Comparison of mohs micrographic surgery and wide excision for extramammary Paget's disease. Dermatol Surg. 2003;29:723-7.

14. Kang Z, Xu F, Zhu Y, Fu P, Zhang QA, Hu T, Li X, Zhang Q, Wu Z, Zhang X et al. Genetic analysis of mismatch repair genes alterations in Extramammary Paget disease. Am J Surg Pathol. 2016;40:1517-25.

15. Kato J, Sumikawa Y, Hida T, Kamiya T, Horimoto K, Kamiya S, Sato S, Takahashi H, Sawada M, Yamashita T. Serum cytokeratin 19 fragment 21-1 is a useful tumor marker for the assessment of extramammary Paget's disease. J Dermatol. 2017;44:666-70.

16. Oji M, Furue M, Tamaki K. Serum carcinoembryonic antigen level in Paget's disease. Br J Dermatol. 1984;110:211-3.

17. Wang J, Chen J, Sen S. MicroRNA as biomarkers and diagnostics. J Cell Physiol. 2016;231:25-30.

18. Lv Y, Qi R, Xu J, Di Z, Zheng H, Huo W, Zhang L, Chen H, Gao X. Profiling of serum and urinary microRNAs in children with atopic dermatitis. PLoS One. 2014;9:e115448.

19. Kanitakis J. Mammary and extramammary Paget's disease. J Eur Acad Dermatol Venereol. 2007:21:581-90.

20. Chanda JJ. Extramammary Paget's disease: prognosis and relationship to internal malignancy. J Am Acad Dermatol. 1985;13:1009-14.

21. Merot Y, Mazoujian G, Pinkus G, Momtaz TK, Murphy GF. Extramammary Paget's disease of the perianal and perineal regions. Evidence of apocrine derivation. Arch Dermatol. 1985:121:750-2.

22. Fujimoto A, Takata M, Hatta N, Takehara K. Expression of structurally unaltered androgen receptor in extramammary Paget's disease. Lab Investig. 2000;80:1465-71.

23. Mazoujian G, Pinkus GS, Haagensen DE Jr. Extramammary Paget's diseaseevidence for an apocrine origin. An immunoperoxidase study of gross cystic disease fluid protein-15, carcinoembryonic antigen, and keratin proteins. Am J Surg Pathol. 1984;8:43-50

24. Hanna W, Alowami S, Malik A. The role of HER-2/neu oncogene and vimentin filaments in the production of the Paget's phenotype. Breast J. 2003;9:485-90.

25. Giger O, Caduff R, O'Meara A, Diener PA, Knuth A, Jager D, Moch $H$, Varga Z. Frequent expression of the breast differentiation antigen NY-BR-1 in mammary and extramammary Paget's disease. Pathol Int 2010;60:726-34

26. Imam A, Yoshida SO, Taylor CR. Distinguishing tumour cells of mammary from extramammary Paget's disease using antibodies to two different glycoproteins from human milk-fat-globule membrane. Br J Cancer. 1988;58:373-8.

27. Tamaki K, Hino H, Ohara K, Furue M. Lectin-binding sites in Paget's disease. Br J Dermatol. 1985;113:17-24.

28. Schwarz LJ, Hutchinson KE, Rexer BN, Estrada MV, Gonzalez Ericsson PI, Sanders ME, Dugger TC, Formisano L, Guerrero-Zotano A, Red-Brewer M, et al. An ERBB1-3 neutralizing antibody mixture with high activity against drug-resistant HER2+ breast cancers with ERBB ligand overexpression. J Nat Cancer Inst. 2017:109:1-10.

29. Choi HJ, Joo HS, Won HY, Min KW, Kim HY, Son T, Oh YH, Lee JY, Kong G. Role of RBP2-induced ER and IGF1R-ErbB signaling in tamoxifen resistance in breast Cancer. J Natl Cancer Inst. 2018;110:1-11.

30. Hou Y, Shen R, Chaudhary S, Tonkovich D, Li Z. Utility of different immunostains for diagnosis of metastatic breast carcinomas in both surgical and cytological specimens. Ann Diagn Pathol. 2017;30:21-7.

31. Wu H, Wang H, Guan S, Zhang J, Chen Q, Wang X, Ma K, Zhao P, Zhao H, Yao W, et al. Cell-specific regulation of proliferation by Ano1/TMEM16A in breast cancer with different ER, PR, and HER2 status. Oncotarget. 2017:8:84996-5013.

32. Kang Z, Zhang Q, Zhang Q, Li X, Hu T, Xu X, Wu Z, Zhang X, Wang H, Xu J, et al. Clinical and pathological characteristics of extramammary Paget's disease: report of 246 Chinese male patients. Int J Clin Exp Pathol. 2015:8:13233-40. 
33. Tian W, Osawa M, Horiuchi H, Tomita Y. Expression of the prolactininducible protein (PIP/GCDFP15) gene in benign epithelium and adenocarcinoma of the prostate. Cancer Sci. 2004;95:491-5.

34. Seipel AH, Samaratunga H, Delahunt B, Wiklund P, Clements M, Egevad L. Immunohistochemistry of ductal adenocarcinoma of the prostate and adenocarcinomas of non-prostatic origin: a comparative study. APMIS. 2016;124:263-70

35. Day KC, Lorenzatti Hiles G, Kozminsky M, Dawsey SJ, Paul A, Broses L, Shah R, Kunja LP, Hall C, Palanisamy N, et al. HER2 and EGFR overexpression support metastatic progression of prostate Cancer to bone. Cancer Res. 2017:77:74-85

36. Peng $Y$, Wang $L, G u$ J. Elevated preoperative carcinoembryonic antigen (CEA) and Ki67 is predictor of decreased survival in IIA stage colon cancer. World J Surg. 2013;37:208-13.

37. Ochs AM, Wong L, Kakani V, Neerukonda S, Gorske J, Rao A, Riggs M, Ward $\mathrm{H}$, Keville L. Expression of vascular endothelial growth factor and HER2/neu in stage II colon cancer and correlation with survival. Clin Colorectal Cancer. 2004;4:262-7.

38. Basova P, Pesta M, Sochor M, Stopka T. Prediction potential of serum miR-155 and miR-24 for relapsing early breast Cancer. Int J Mol Sci. 2017;18:E2116.

39. Wang F, Zheng Z, Guo J, Ding X. Correlation and quantitation of microRNA aberrant expression in tissues and sera from patients with breast tumor. Gynecol Oncol. 2010;119:586-93.

40. Gasparini P, Lovat F, Fassan M, Casadei L, Cascione L, Jacob NK, Carasi S, Palmieri D, Costinean S, Shapiro CL, et al. Protective role of miR-155 in breast cancer through RAD51 targeting impairs homologous recombination after irradiation. Proc Natl Acad Sci U S A. 2014;111:4536-41.

41. Cai ZK, Chen Q, Chen YB, Gu M, Zheng DC, Zhou J, Wang Z. microRNA-155 promotes the proliferation of prostate cancer cells by targeting annexin 7 . Mol Med Rep. 2015;11:533-8.

42. Yang H, Liu C, Zhang YQ, Ge LT, Chen J, Jia XQ, Gu RX, Sun Y, Sun WD. llexgenin a induces B16-F10 melanoma cell G1/S arrest in vitro and reduces tumor growth in vivo. Int Immunopharmacol. 2015;24:423-31.

43. Cao H, Huang S, Liu A, Chen Z. Up-regulated expression of miR-155 in human colonic cancer. J Cancer Res Ther. 2018;14:604-7.

44. Forzati F, De Martino M, Esposito F, Sepe R, Pellecchia S, Malapelle U, Pellino $\mathrm{G}$, Arra C, Fusco A. miR-155 is positively regulated by CBX7 in mouse embryonic fibroblasts and colon carcinomas, and targets the KRAS oncogene. BMC Cancer. 2017;17:170.

Ready to submit your research? Choose BMC and benefit from:

- fast, convenient online submission

- thorough peer review by experienced researchers in your field

- rapid publication on acceptance

- support for research data, including large and complex data types

- gold Open Access which fosters wider collaboration and increased citations

- maximum visibility for your research: over $100 \mathrm{M}$ website views per year

At BMC, research is always in progress.

Learn more biomedcentral.com/submissions 